\title{
Population dynamics of Diplolaimelloides bruciei, a nematode associated with the salt marsh plant Spartina anglica*
}

\author{
R. Alkemade **, A. Wielemaker, P. M. J. Herman, M. A. Hemminga \\ Netherlands Institute of Ecology, Centre for Estuarine and Coastal Ecology, Vierstraat 28, 4401 EA Yerseke, The Netherlands
}

\begin{abstract}
The halophyte Spartina anglica, which occurs abundantly in the lower parts of Western European salt marshes, contains large amounts of standing dead plant material year round, supporting a rich faunal community. The population dynamics of Dipolaimelloides bruciei, one of the dominant nematode species present on S. anglica, was studied in relation to the decomposition stage of the plant material. $S$. anglica vegetations are regularly flooded at high tide, reducing the nematode population density on the plant material as nematodes are flushed from the plants. The extent of population reduction by flooding was studied in a laboratory experiment using litter of 2 different decomposition stages. D. bruciei was present throughout the year on all types of plant material, including live green plant parts. The population densities were highest on the older plant material, reaching 1000 to 2000 ind. $\mathrm{g}^{-1}$ in late summer and autumn. In the laboratory the rate of removal by flooding was 4.4 times higher on brown leaves than on yellow leaves, while the birth rates were almost identical. As a result the population on yellow leaves increased at a much higher rate than on brown leaves and reached much higher densities. The total number and biomass of $D$. bruciei formed in the $S$. anglica vegetation were calculated, assuming that the birth rate of the species depended only on temperature, to be 9 million ind. $\mathrm{m}^{-2}$ $\mathrm{yr}^{-1}$ accounting for $114 \mathrm{mg} \mathrm{C} \mathrm{m}{ }^{-2}$. The total amount of carbon ingested by $D$. bruciei as bacterial biomass accounted for $7.5 \%$ of the total bacterial biomass produced. The dominant bacterivorous nematodes together may remove over $20 \%$ of the total bacterial biomass.
\end{abstract}

KEY WORDS: Decomposition · Flooding - Nematodes · Population dynamics

\section{INTRODUCTION}

In the lower zone of Western European salt marshes, Spartina anglica can form extensive monospecific vegetations. On these sites relatively large amounts of standing dead plant material is found year round (Wolff et al. 1979, Groenendijk 1984). Export of plantderived detritus from European coastal salt marshes is probably insignificant (Hemminga et al. 1992, 1993). The major part of the dead plant material, therefore, will decompose at the production site. Decomposing

- Communication no. 685 of the Centre for Estuarine and Coastal Ecology

- Present address: National Institute for Public Health and Environmental Protection, Laboratory LBG, PO Box 1, 3720 BA Bilthoven, The Netherlands leaves remain attached to standing stems for a prolonged period (Newell et al. 1989). Dead plant material of different stages of senescence and decay can be found in the canopy; senescent and dead leaves attached to the still green culms and old, dead culms with barely any leaves are simultaneously present.

Decomposition is largely a microbial process, but is influenced by the faunal community, which may consist of macro-, meio- and microfaunal species (Swift et al. 1979). In salt marshes especially, nematodes are abundantly present on decomposing Spartina anglica litter (Buth \& de Wolf 1985, Hemminga \& Buth 1991). Diplolaimelloides bruciei is one of the dominant nematode species present on living and dead $S$. anglica leaves (Hopper 1970, Warwick 1981, Bouwman et al. 1984). D. bruciei is scarcely found in the surrounding sediment, indicating that $D$. bruciei is narrowly asso- 
ciated with $S$. anglica litter (Bouwman et al. 1984). In a previous study, we found that $D$. bruciei can stimulate bacterial decomposition of $S$. anglica leaves under laboratory conditions (Alkemade et al. 1992). The effect of $D$. bruciei on the decomposition of $S$. anglica is expected to depend on nematode population density and on the total number of nematodes formed, including the individuals lost due to death, flooding, etc. The study of population growth and of population density is therefore considered important to assess the potentially stimulating effects of the nematodes under field conditions.

The population density of Diplolaimelloides bruciei probably depends on at least 3 factors. Firstly, since $D$. bruciei is a bacterivorous nematode (Romeyn \& Bouwman 1983, Nicholas 1984), the population density is expected to depend on the bacterial biomass production. Secondly, the population growth rate of $D$. bruciei depends on temperature (Warwick 1981) and population growth will therefore fluctuate seasonally. Thirdly, flooding by seawater is expected to remove nematodes and thus will decrease population densities (cf. Fleeger et al. 1984).

In this study we investigated the population dynamics of Diplolaimelloides bruciei on standing live and dead plants of Spartina anglica in a salt marsh in the SW Netherlands. Monthly samples of above-ground $S$. anglica, consisting of visually distinguishable stages of decomposition, were collected and the nematode population associated with the plant material was analyzed. The population growth of $D$. bruciei on $S$. anglica litter of different decomposition stages was also studied in laboratory experiments. A facility to simulate flooding was used to assess the influence of flooding on population densities present on the different litter types. Finally, an estimation of the proportion of the bacterial biomass consumed by $D$. bruciei was made.

\section{MATERIAL AND METHODS}

Field study. Samples of Spartina anglica were collected in a salt marsh (called Rattekaai), situated in the Oosterschelde, a ticial inlet of the southern North Sea. The samples were taken in a $100 \mathrm{~m}^{2}$ area near the edge of the salt marsh where $S$, anglica forms an almost monospecific vegetation. Salicornia sp. was also present in very low densities. The elevation of the site was $1.67 \mathrm{~m}$ above Dutch Ordnance Level (NAP).

Three paired randomly selected samples were collected monthly from 20 September 1990 to 15 August 1991. Small quadrats $\left(0.04 \mathrm{~m}^{2}\right)$ were harvested by cutting the plants at the sediment surface. The plant material was put into plastic bags and transported to the laboratory where all samples were divided into 4 different categories: 'living green biomass'; 'greenishyellow leaves', with the stem parts bearing these leaves; 'dead brown leaves', again with the stem parts bearing theses leaves; and 'old stems', brown culms without any leaves. If the lower parts of the stems were covered by a layer of sediment, these parts were discarded, because nematode densities and species composition are highly influenced by this layer (Bouwman et al. 1984). One sample of a pair was dried at $70^{\circ} \mathrm{C}$ for $48 \mathrm{~h}$ in order to obtain dry weight estimates of the 4 different categories of plant material. The other sample was fixed in warm $4 \%$ formalin to preserve the nematodes.

Nematodes were extracted from the plant material by rinsing the samples with tap water over a household sieve ( $2 \mathrm{~mm}$ mesh). Nematodes and other particles passed through the sieve whereas the coarse plant material was retained. The plant material was dried and weighed. The suspension containing the nematodes was further processed using centrifugation as described in Alkemade et al. (1993). In each sample, the total number of nematodes was counted under a dissecting microscope. A total of 100 nematodes were identified and the number and biomass of Diplolaimelloides bruciei were estimated in 1 of the 3 samples of each category collected each month.

Differences among total nematode densities and among densities of Diplolaimelloides bruciei on the different categories of Spartina anglica material were evaluated by analysis of covariance. The relations between nematode densities, temperature and flooding frequency were evaluated by regression analysis. Densities were log-transformed prior to analysis. The monthly average air temperature measured at Vlissingen (data obtained from the Royal Dutch Meteorological Institute) and the flooding frequency between sampling days, derived from the high tide levels recorded at the nearby point of Marollegat (data obtained from the Ministry of Transport and Public Works, Tidal Waters Division), were used in the analysis.

Laboratory experiment. Two separate experiments with brown and yellow-greenish leaves were carried out in October/November 1991 and February/March 1992. Leaves were collected at the Rattekaai salt marsh. The leaves were washed with tap water and dried at air temperature. The leaf material was sterilized by gamma irradiation (2 Mrad) at a facility for food irradiation (Proefbedrijf voor Voedselbestraling Wageningen).

The leaves were cut into $3 \mathrm{~cm}$ long fragments and put into small nylon bags with $1 \mathrm{~mm}$ mesh. Each bag received ca $0.5 \mathrm{~g}$ DW. The bags were soaked in sterile, filtered seawater for about $2 \mathrm{~h}$. All bags were inocu- 
lated with $100 \mu \mathrm{l}$ of a microbial assemblage. This assemblage was obtained by rinsing Spartina anglica plant material originating from the Rattekaai salt marsh with sterile seawater and filtering the water over a $1.2 \mu \mathrm{m}$ filter. Specimens of Diplolaimelloides bruciei obtained from cultures (see Alkemade et al. 1992) were also added to each bag. The initial nematode population density was determined after $2 \mathrm{~d}$ of incubation.

A total of 20 bags were placed in a 11 glass jar and transferred to an incubator $\left(20^{\circ} \mathrm{C}\right)$. Flooding was simulated 4 times a week by pumping filtered and autoclaved Oosterschelde seawater into the glass jar. The jar was filled within $30 \mathrm{~min}$ at a rate of $15 \mathrm{ml} \mathrm{min}^{-1}$. The water remained $2 \mathrm{~h}$ in the jar before it was pumped back into a bottle. The water in the bottle was renewed 2 times a week. Nematode numbers were counted in a $10 \mathrm{ml}$ sample of the water that was removed from the bottle. Two replicate jars were prepared for each experiment. Once a week 2 bags were removed from each jar. One bag was dried and weighed to determine weight loss. The other bag was fixed in warm formalin $(4 \%)$ and the number of nematodes determined. The experiments lasted $42 \mathrm{~d}$.

The population density on the Spartina anglica material was assumed to be determined by the rate of removal of nematodes from the litter and the population growth rate. An exponential growth model with a constant rate of removal by flooding was adopted to describe the population dynamics of Diplolaimelloides bruciei. It was assumed that birth rate minus death rate remained constant during the experiment, resulting in a net growth rate. Furthermore, it was assumed that the rate of removal by flooding was the only source of disappearance apart from death. The model can be described by the following equation:

$$
N_{1}=N_{0} \mathrm{e}^{(\beta-\alpha) t}
$$

where $N_{t}=$ number of nematodes present on the $S$. anglica detritus at time $t ; N_{0}=$ number of nematodes present at the start of the experiment; $\beta=$ growth rate; and $\alpha=$ rate of nematodes flushing due to flooding. The flooding parameter can be estimated independently of $\beta$ by using the number of nematodes flushed away and the number of nematodes present on the leaves. As the days on which the bags were removed from the jar did not coincide with the days on which the flushing took place, the number of nematodes present on the leaves at the moment of flushing was calculated by linear interpolation between the sampling days. $\alpha$ was found by linear regression of the number of nematodes flushed away per unit time on the number of nematodes present on the $S$. anglica leaves. It was assumed that the errors in the observations had a Poisson distribution, as the data were counts. The parameters were estimated using maximum likelihood estimation (McCullagh \& Nelder 1989). Using the calculated values for $\alpha$, the growth rate $\beta$ was then calculated by nonlinear regression of the exponential growth equation (Eq. 1). Again the errors were assumed to have a Poisson distribution and maximum likelihood estimation was used to estimate the parameters. Subsequently, the total numbers developed during the course of the experiments were estimated by integrating growth $\beta$ over time:

$$
P=\int_{0}^{T} \beta N \mathrm{~d} t
$$

where $P=$ the total number of nematodes; and $T=$ the last day of the experiment.

The regression analyses were carried out using SYSTAT 5.0 (Wilkinson 1990) and the total number of nematodes formed was calculated by numerical integration using SENECA 1.5 (De Hoop et al. 1992).

\section{RESULTS}

\section{Field study}

Green biomass of Spartina anglica showed a clear seasonal pattern (Fig. 1). In August a maximum of $850 \mathrm{~g} \mathrm{DW} \mathrm{m}^{-2}$ of green biomass was reached. Green $S$. anglica leaves were found year round, but in winter months only a very low biomass was observed. Yellow leaves were also found in most of the samples. The peak amount of $200 \mathrm{~g} \mathrm{DW} \mathrm{m}^{-2}$ of yellow leaves was found in January. Older plant material of the categories 'brown' and 'old stems' were found throughout the year in relatively constant amounts. The total dead biomass, consisting of the categories 'yellow', 'brown'

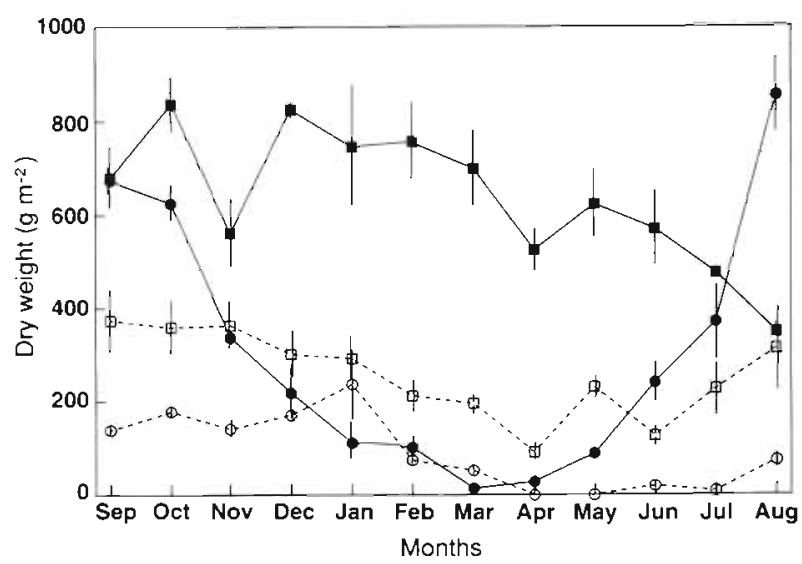

Fig. 1. Spartina anglica. Dry weights ( $\mathrm{g} \mathrm{m}^{-2}$, mean $\pm \mathrm{SE}, \mathrm{n}=3$ ) of 4 categories of standing plant material in the salt marsh $(\bullet$ Living green biomass; (O) yellow leaves; $(\mathbf{})$ brown leaves; (ㅁ) old stems 
and 'old stems', exceeded the biomass of the green plant parts in every month except August.

The total nematode densities, all species included, expressed as numbers per $g$ dry weight (DW) of plant material, are shown in Fig. 2A. The numbers found on brown and old material were usually higher than on yellow and green leaves and showed little seasonal variation. The numbers fluctuated between 1000 and 4000 ind. $\mathrm{g}^{-1} \mathrm{DW}$. The numbers of nematodes on green and yellow plant parts were usually much lower, but showed a sharp peak in March and June, respectively. The total numbers per $\mathrm{m}^{2}$ of Spartina anglica vegetation fluctuated from about 1 million in spring and summer to 2 to 3 million in autumn (Fig. 2B).

Diplolaimelloides bruciei was found in all samples. Densities differed significantly between the various Litter categories $(p<0.05)$. For this test we assumed that the observations from the different sampling dates were replicates. On the brown plant parts and the old
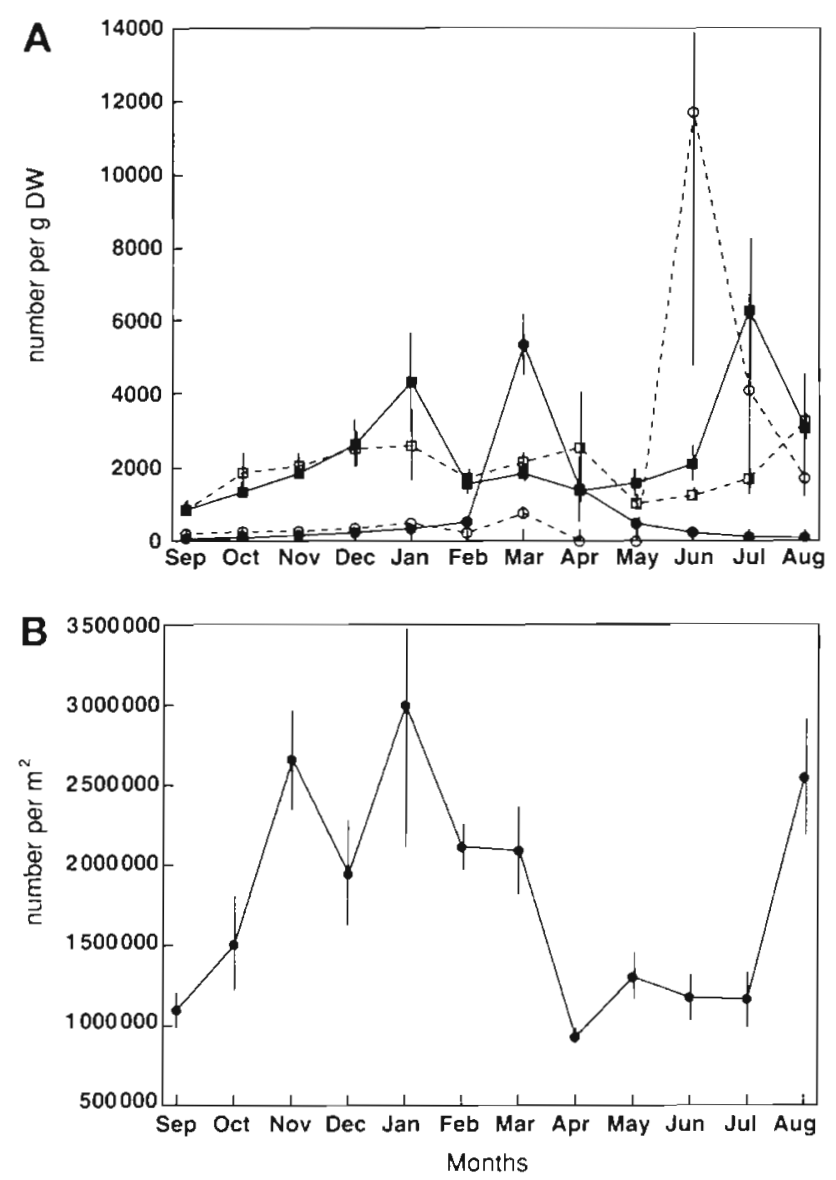

Flg. 2. Nematodes living on Spartina anglica. (A) Densities (ind $\mathrm{g}^{-1} \mathrm{DW}$ ) of all species of nematodes on 4 categories of standing plant material: $(\bullet)$ living green biomass; ( 0 ) yellow leaves; ( $\square$ ) brown leaves; ( $($ ) old stems. (B) Total number of nematodes (ind. $\mathrm{m}^{-2}$ ) on aboveground plant parts. Means $\pm S E, n=3$ stems, population densities were usually higher than on the green and yellow plant parts (Tukey's test, $p<0.05$ ). Population density on the green leaves was usually lower than 100 ind. $\mathrm{g}^{-1} \mathrm{DW}$, but a much higher density was found in the March sample (Fig. 3). On yellow leaves the population density was usually about 100 ind. $\mathrm{g}^{-1} \mathrm{DW}$, but higher population densities were found in the summer reaching a maximum of more than 2000 ind. $\mathrm{g}^{-1}$ DW in July. On brown plant parts, population densities were highest in summer (July and August), and reached densities of 1400 ind $\mathrm{g}^{-1} \mathrm{DW}_{;}$in the other seasons the numbers of $D$. bruciei were much lower. On old stems a similar pattern was observed; the highest numbers were found in summer. In Fig. 4 the relative abundance of $D$. bruciei is shown. In September 1990 and in August 1991 the relative abundance of D. bruciei was 38 and $45 \%$ respectively (Fig. 4 ). In the winter months $D$. bruciei did not dominate: less than $12 \%$ of the total number were of this species in December 1990, January and February 1991. On average, D. bruciei formed $20 \%$ of the total nematode community on the Spartina anglica plants.

Regression analyses showed that the log-transformed nematode densities were not related to the flooding frequency ( $p>0.5$ for all categories of plant parts). The lognumbers of nematodes on yellow and on brown leaves were highly correlated with the mean monthly temperature $(\mathrm{p}<0.01)$. On green plant parts and old stems no correlation was found between the nematode densities and the temperature $(p=0.67$ and 0.19 , respectively).

\section{Laboratory study}

During the experiments the weight of Spartina anglica leaves in the litter bags decreased gradually.

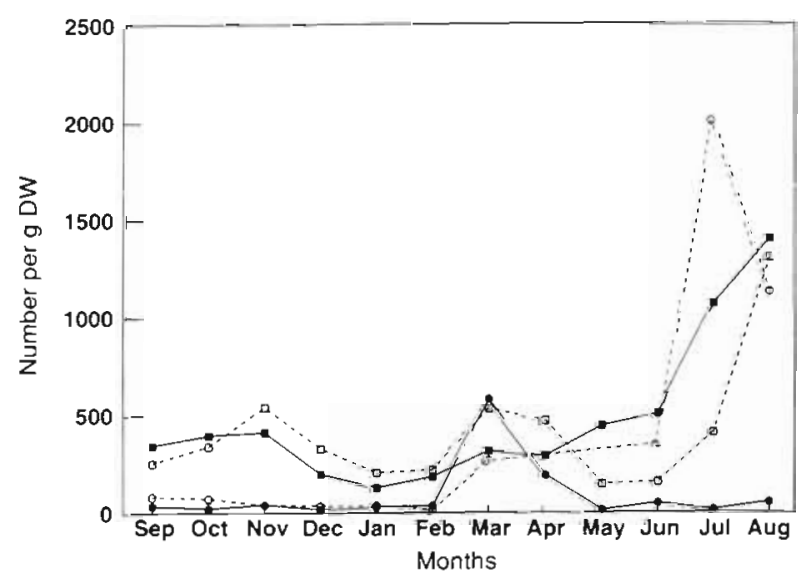

Fig. 3. Diplolaimelloides bruciei living on Spartina angluca. Densities on 4 categories of standing plant material. (•) Living green biomass; ( 0 ) yellow leaves; ( $\bullet$ ) brown leaves, () old stems 


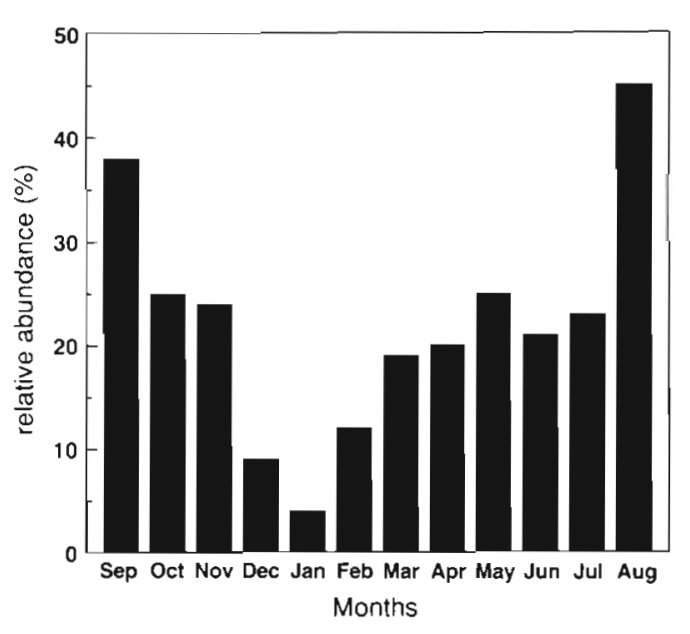

Fig. 4. Diplolaimelloides bruciei living on Spartina anglica. Abundances relative to the total nematode community present

The weight losses from the yellow leaves were higher than from the brown leaves. After $42 \mathrm{~d}$ the yellow leaves lost, on average, $32 \%$ of the initial weight, whereas the brown leaves lost $<10 \%$.

The initial nematode population on the yellow leaves was smaller than on the brown leaves. At the first sampling date, $2 \mathrm{~d}$ after inoculation, 25 ind. $\mathrm{g}^{-1} \mathrm{DW}$ were found on the yellow leaves and 300 ind. $\mathrm{g}^{-1} \mathrm{DW}$ on the brown leaves. These figures were used in the calculation of the population growth parameters. Conspicuously more nematodes were flushed away from the brown leaves, relative to the numbers in the litter bags, than from the yellow leaves. In Fig. 5, the numbers flushed away during 1 flushing time are plotted against the numbers present on the leaves. The flooding parameter $\alpha$ was 4.4 times higher on brown leaves than on

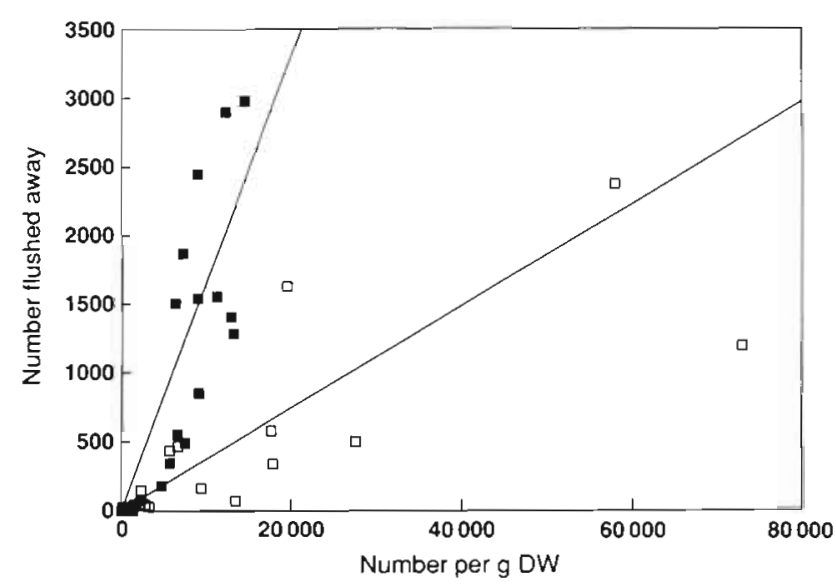

Fig. 5. Diplolaimelloides bruciei living on Spartina anglica. Numbers flushed away from yellow ( $\square$ ) and brown ( $\square$ ) leaves plotted against the number present on decomposing leaves yellow leaves, 0.164 and 0.037 per flushing time respectively. Apparently $\alpha$ depended largely on litter type. These figures and the initial population densities were used to calculate the birth rate $\beta$. Since the flooding parameter $\alpha$ was calculated as a rate per flushing time and flushing occurred 4 times a week, these parameters had to be transformed to rates per day by dividing the parameters by 1.75. In Fig. 6 the growth curves of the populations on yellow and on brown leaves are shown. The prolonged initial phase of population growth on yellow leaves is due to the lower initial population density. At the end of the experiment much higher densities were reached on yellow leaves than on brown leaves. The calculated birth rates in both populations were almost identical: $0.206( \pm 0.008,95 \% \mathrm{CL})$ on yellow leaves and 0.197 ( $\pm 0.01,95 \% \mathrm{CL}$ ) on brown leaves. The calculated total number of nematodes formed was 55800 on yellow leaves and 42000 on brown leaves. The difference between these 2 numbers was low in comparison with the population densities present at the end of the experiment, ca 56000 on yellow leaves and ca 11500 on brown leaves.

\section{DISCUSSION}

The Spartina anglica vegetation in the Rattekaai salt marsh contains a large proportion of dead plant material. More dead plant material was found than green, live plant material almost year round. Nematodes were present throughout the year on green plant parts as well as on senescent and decaying plant parts. The highest numbers of nematodes per $\mathrm{m}^{2}$ were found during the autumn and winter, coinciding with the highest amounts of dead plant material present on the salt marsh. The total numbers of nematodes ranged

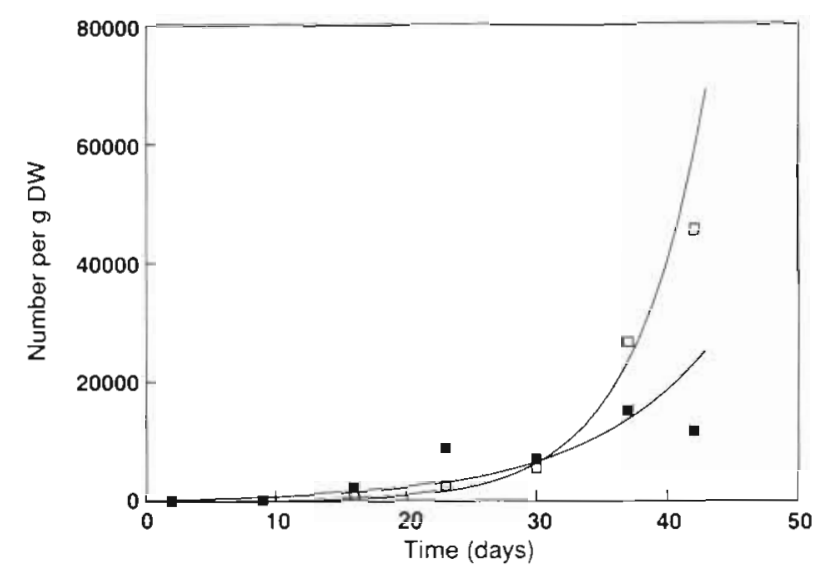

Fig. 6. Diplolaimelloides bruciei living on Spartina anglica. Population growth on yellow (ㅁ) and brown ( leaves. Fitted lines are exponential growth curves 
from $1 \times 10^{6}$ to $3 \times 10^{6} \mathrm{~m}^{-2}$. These numbers are of the same magnitude as the numbers found in salt marsh and estuarine sediments; the total number in the sediment supporting $S$. anglica vegetation varied from 2 to 10 million ind. $\mathrm{m}^{-2}$ (Alkemade et al. 1993), and in coastal sediments usually densities between 1 and 20 million ind. $\mathrm{m}^{-2}$ are observed (e.g. Teal \& Wieser 1966, Warwick \& Price 1979, Heip et al. 1985). Thus, the nematode community living on the standing dead plant parts forms a substantial part of the total salt marsh nematofauna.

The bacterivorous nematode Diplolaimelloides bruciei is one of the dominant species present on the aboveground plant parts, representing up to $50 \%$ of the nematodes in late summer and autumn. Bouwman et al. (1984) found similar percentages for $D$. bruciei on Spartina anglica vegetation in the northeastern part of The Netherlands. The numbers of $D$. bruciei found in the field were much lower than the densities observed under laboratory conditions, which possibly is due to the more moderate conditions in the laboratory. In the field, temperature fluctuates much more than in the laboratory and usually does not reach values over $20^{\circ} \mathrm{C}$. Flooding is irregular and probably often more vigorous than in the laboratory experiment, causing higher losses of nematodes from the population.

In the laboratory experiment the population dynamics of Diplolaimelloides bruciei could be described by an exponential growth model, consisting of 2 components: a constant growth rate and a constant rate of loss of nematodes as a result of flushing. The results showed that the birth rates were almost identical on both leaf types $(0.206$ and 0.197 on yellow and brown leaves respectively) and were close to the value of $0.21 \mathrm{~d}^{-1}$ found by Warwick (1981) for the rate of population increase of the same species at $20^{\circ} \mathrm{C}$. The pre- sent values are also consistent with our earlier estimate of $0.22 \mathrm{~d}^{-1}$ (Alkemade et al. 1992). The growth of the nematode population on the different leaf types was mainly affected by flooding. On brown leaves the proportion of nematodes flushed away relative to the population density present on the leaves was 4.4 times higher than on the yellow leaves. This may be caused by the fact that the surface properties of the leaf litter alters with age. During decomposition the leaves disintegrate to tangles of long shreds (Newell et al. 1989). At the beginning of the experiments both leaf types had clear surface structures consisting of longitudinal grooves. Nematodes may be relatively protected against the risk of being flushed away in these grooves. The brown leaves lost this surface structure within a few weeks. As a result, nematodes may lose their 'grip' and consequently are flushed away during high tide. The structure of the yellow leaves, in contrast, remained much more intact during the experiment, which may have enabled the nematode population to reach relatively high densities.

The disappearance of large numbers of nematodes from disintegrating leaves is not necessarily a loss to the population. Some of these nematodes may reach other Spartina anglica sites. We observed that Diplolaimelloides bruciei remained in suspension for several hours, sufficiently long to migrate within a salt marsh during high tide.

In the field the numbers of Diplolaimelloides bruciei were usually highest on the older plant litter of the categories 'brown' and 'old stems'. Only in late summer did the numbers found on yellow leaves exceed the numbers on brown leaves and old stems. During the first phases of decomposition the population density apparently increases from the low numbers found on yellow leaves to the high numbers found on brown

Table 1. Diplolaimelloides bruciei. Estimation of monthly production. For calculation of $\mathrm{C}$ production, a nematode $\mathrm{C}$ content of $10.6 \%$ of wet weight was assumed (Heip et al. 1985)

\begin{tabular}{|c|c|c|c|c|c|c|}
\hline \multirow[t]{2}{*}{ Month } & \multirow{2}{*}{$\begin{array}{l}\text { Mean temperature } \\
\qquad\left({ }^{\circ} \mathrm{C}\right\}\end{array}$} & \multirow{2}{*}{$\begin{array}{l}\text { Growth rate } \\
\qquad\left(\mathrm{d}^{-1}\right)\end{array}$} & \multirow{2}{*}{$\begin{array}{l}\text { Density } \\
\left.\text { (ind. } \mathrm{m}^{-2}\right)\end{array}$} & \multirow{2}{*}{$\begin{array}{l}\text { Mean wet wt } \\
\left(\mu \text { ind }^{-1}\right)\end{array}$} & \multicolumn{2}{|c|}{ Production } \\
\hline & & & & & ind. $\mathrm{m}^{-2}$ & $\mathrm{mg} C \mathrm{~m}^{-2}$ \\
\hline Sep 90 & 14.7 & 0.13 & 303700 & 0.144 & 1184400 & 18.1 \\
\hline Oct 90 & 13.1 & 0.11 & 221800 & 0.156 & 722100 & 11.9 \\
\hline Nov 90 & 7.8 & 0.04 & 390700 & 0.130 & 439700 & 6.1 \\
\hline Dec 90 & 5.1 & 0.001 & 136300 & 0.126 & 5500 & 0.1 \\
\hline Jan 91 & 4.1 & 0.0 & 102100 & 0.130 & 0 & 0.0 \\
\hline Feb 91 & 0.5 & 0.0 & 163100 & 0.117 & 0 & 0.0 \\
\hline Mar 91 & 8.1 & 0.04 & 231600 & 0.222 & 288600 & 6.8 \\
\hline Apr 91 & 8.8 & 0.05 & 153100 & 0.184 & 233900 & 4.6 \\
\hline May 91 & 10.0 & 0.07 & 177500 & 0.184 & 356800 & 7.0 \\
\hline Jun 91 & 13.1 & 0.11 & 207700 & 0.133 & 676200 & 9.5 \\
\hline Jul 91 & 18.2 & 0.18 & 247800 & 0.118 & 1314700 & 16.4 \\
\hline Aug 91 & 18.8 & 0.18 & 662200 & 0.086 & 3673700 & 33.5 \\
\hline Total & & & & & 8895600 & 114.0 \\
\hline
\end{tabular}


leaves. Probably, as discussed above, the numbers decrease again as the leaves gradually lose their surface structure. In the laboratory experiments the nematode population reached much higher densities on the (initially) yellow leaves than on brown leaves, since the yellow leaves had changed into 'brown' leaves at the end of the experiment, whereas the initially brown leaves lost their leaf-surface structure in the course of the experiment, resulting in large losses during flooding. On the stems the changes in population density are probably slower, since the stems disintegrate at a much slower rate.

With the data available it is possible to make an estimate of the total number and biomass of Diplolaimelloides bruciei formed on a Spartina anglica vegetation and of the bacterial biomass consumed by the nematodes. The total amount of $S$. anglica detritus formed approximately equals the total yearly production of the macrophyte. The peak above-ground living biomass can be considered as a rough estimate of the yearly production of $S$. anglica (De Leeuw et al. 1991). The peak above-ground living biomass at the Rattekaai salt marsh occurred in August, being $850 \mathrm{~g} \mathrm{DW}$ $\mathrm{m}^{-2}$, equivalent to $\pm 340 \mathrm{~g} \mathrm{C} \mathrm{m}^{-2}$. The nematode production depends on the number of nematodes present at the sampling time and the growth rate of the nematodes (Heip et al. 1982):

$$
P=\sum r_{i} N_{i}
$$

where $P=$ production, $r_{i}=$ arithmetic growth rate; and $N_{i}$ the number of nematodes in the $i$ th sampling interval. Warwick (1981) showed that the growth rate depended on temperature and derived a linear regression formula for the relation between the birth rate and the temperature. Using this formula the average monthly growth rate of every month was calculated from the mean monthly temperatures. In Table 1 the mean monthly temperature, the calculated growth rates, the total number of $D$. bruciei $\mathrm{m}^{-2}$ and the estimated daily total number of nematodes formed are shown. An estimate of the total number of $D$. bruciei formed during the year was obtained by summing the daily production of new nematodes, and was approximately 8.89 million ind. $\mathrm{m}^{-2} \mathrm{yr}^{-1}$.

The mean biomass per individual was calculated each sampling day (Table 1). The total biomass production, calculated from these figures, was approximately $1.07 \mathrm{~g}$ wet weight, equivalent to $114 \mathrm{mg} \mathrm{C} \mathrm{m}^{-2}$, which represents only a small fraction of the Spartina anglica production. The amount of bacteria ingested by the nematodes is much higher than the biomass produced, since a large amount of bacterial $\mathrm{C}$ ingested by the nematodes is lost by defecation, excretion and respiration. The fraction of the bacterial $C$ ingested which is transferred to biomass of Diplolaimelloides bruciei is not known. Herman \& Vranken (1988) gave estimates of the assimilation efficiency and the production efficiency of the related species Monhystera disjuncta. When we assume that the efficiency of $D$. bruciei is similar to that of $M$. disjuncta, the fraction of bacterial $C$ transfered into nematode biomass can be considered as the product of the assimilation efficiency and the production efficiency, and equals approximately 0.15 . Thus, to form $114 \mathrm{mg} C$ of nematode biomass, $760 \mathrm{mg} \mathrm{C} \mathrm{m}^{-2}$ of bacterial biomass is needed.

If Spartina anglica carbon is transformed into bacterial biomass with an efficiency of $10 \%$, the maximum total bacterial biomass formed is equal to $34 \mathrm{~g} \mathrm{C} \mathrm{m}^{-2}$ $\mathrm{yr}^{-1}$. This figure, however, is unrealistically high, since only a part of the $S$. anglica detritus is decomposed by bacteria. Another part is decomposed by fungi or is removed from the salt marsh by the tides. Padgett et al. (1985) estimated that about $30 \%$ of $S$. alterniflora leaves were decomposed by bacteria. The total bacterial biomass formed may be equivalent to $10 \mathrm{~g} \mathrm{C} \mathrm{m}^{-2}$ $\mathrm{yr}^{-1}$. Thus the bacterial biomass ingested by Diplolaimelloides bruciei may account for $7.5 \%$ of the total bacterial biomass formed during decomposition of $S$. anglica litter. $D$. bruciei was not the only bacterivorous nematode present on $S$. anglica leaves. The numbers of Monhystera disjuncta and Pellioditis marina were of the same order as the numbers of $D$. bruciei. If equal growth is assumed for the 3 bacterivorous nematodes, the ingested proportion of bacterial biomass may be over $20 \%$.

\section{LITERATURE CITED}

Alkemade R., Wielemaker, A., Hemminga, M. A. (1992) Stimulation of decomposition of Spartina anglica leaves by the bacterivorous nematode Diplolaimelloides bruciei (Monhysteridae). J. exp. mar. Biol. Ecol. 159: 267-278

Alkemade, R., Wielemaker, A., Hemminga, M. A. (1993). Correlation between nematode abundance and decomposition rate of Spartina anglica leaves. Mar. Ecol. Prog. Ser. 99: 293-300

Bouwman, L. A., Romeyn, K., Kremer, D. R., van Es, F. B (1984). Occurrence and feeding biology of some nematode species in estuarine aufwuchs communities. Cah. Biol mar. 25: 287-303

Buth, G. J. C., de Wolf, L. (1985). Decomposition of Spartina anglica, Elytrigia pungens and Halimione portulacoides in a Dutch salt marsh in association with faunal and habitat influences. Vegetatio 62: 337-355

De Hoop, B. J., Scholten, H., Herman, P. M. J., Soetaert, K (1992). SENECA 1.5, a simulation environment for ecological application. Netherlands Institute of Ecology, Centre for Estuarine and Coastal Ecology, Yerseke

De Leeuw, J., Buth, G. J. (1991). Spatial and temporal variation in peak standing crop of European tidal marshes. In Elliott, M., Ducrotoy, J. P. (eds.) Estuaries and coasts: spatial and temporal intercomparisons. ECSA 19 symposium. Olsen \& Olsen, Copenhagen

Fleeger, J. W., Chandler, G. T., Fitzhugh, G. R., Phillips, F. E. (1984). Effects of tidal currents on meiofaunal densities in 
vegetated salt marsh sediments. Mar. Ecol. Prog. Ser. 19 $49-53$

Groenendijk, A. M. (1984). Primary production of four dominant salt-marsh angiosperms in the SW Netherlands. Vegetatio 57: 143-152

Heip, C., Herman, P. M. J., Coomans, A. (1982). The productivity of marine meiobenthos. Academiae Analecta (Meded. K. Acad. Wet. Lett. Schone Kunsten Belg. KI Wet.) 44:1-20

Heip, C., Vincx, M., Vranken, G. (1985). The ecology of marine nematodes. Oceanogr. mar. Biol. A. Rev. 23: 399-489

Hemminga, M. A., Buth, G. J. C. (1991). Decomposition in sait marsh ecosystems of the S.W. Netherlands: the effects of biotic and abiotic factors. Vegetatio 92: 73-83

Hemminga, M. A., Klap, V. A., van Soelen, J., Boon, J. J. (1993). The effect of salt marsh inundation on estuarine particulate organic matter characteristics. Mar. Ecol. Prog. Ser. 99: 153-161

Hemminga, M. A., Klap, V. A., van Soelen, J., de Leeuw, J., Boon, J. J. (1992). Shifts in seston characteristics after inundation of a European coastal salt marsh. Limnol. Oceanogr. 37: 1559-1564

Herman, P. M. J., Vranken, G. (1988). Studies of the lifehistory and energetics of marine and brackish-water nematodes: II. Production, respiration and food uptake by Monhystera disjuncta. Oecologia 77: 457-463

Hopper, B. E. (1970). Diplolaimelloides bruciei n. sp. (Monhysteridae: Nematoda), prevalent in marsh grass, Spartina alterniflora Loisel. Can. J. Zool. 48: 573-575

McCullagh, P., Nelder, J. R. (1989). Generalized linear models. Chapman and Hall, London

This article was submitted to the editor
Newell, S. Y, Fallon, R. D., Miller, J. D. (1989). Decomposition and microbial dynamics for standing, naturally positioned leaves of salt-marsh grass Spartina altemiflora. Mar. Biol. 101: $471-481$

Nicholas, W. L. (1984). The biology of free-living nematodes. Clarendon Press, Oxford

Padgett, D. E., Hackney, C. T., Sizemore, R. K. (1985). A technique for distinguishing between bacterial and nonbacterial respiration in decomposing Spartina alterniflora. Hydrobiologia 122: 113-119

Romeyn, K., Bouwman, L. A. (1983). Food selection and consumption by estuarine nematodes. Hydrobiol. Bull. 17: 103-109

Swift, M. J., Heal, O. W., Anderson, J. M. (1979). Decomposition in terrestrial ecosystems. Blackwell Scientific Publications, Oxford

Teal, J. M., Wieser, W. (1966). The distribution and ecology of nematodes in a Georgia salt marsh. Limnol. Oceanogr. 11: $217-222$

Warwick, R. M. (1981). The influence of temperature and salinity on energy partitioning in the marine nematode Diplolaimelloides bruciei. Oecologia 51: 318-325

Warwick, R. M., Price, R. (1979). Ecological and metabolic studies on free-living nematodes from an estuarine mudflat. Estuar. coast. mar. Sci. 9: 257-271

Wilkinson, L. (1990). SYSTAT: the system for statistics. SYSTAT, Inc., Evanston, IL

Wolff, W. J., van Eeden, M. J., Lammens, E. (1979). Primary production and import of particulate organic matter on a salt marsh in the Netherlands. Neth. J. Sea Res. 13: 242-255

Manuscript first received: July 1, 1993

Revised version accepted: December 9, 1993 